\title{
Outplacement Counsellors: Examining Their Work Values, Personality Traits, and Career Success
}

\author{
Manuela Richter ${ }^{1}$, Cornelius J. König ${ }^{1 *}$, Dennis Etzl ${ }^{1}$
}

\begin{abstract}
Outplacement counsellors help people who have been laid off to find a new job, and their personal characteristics are likely to determine the quality of their services. This study examined 50 German outplacement counsellors and, to anchor the description, compared them to 52 psychotherapists, because both groups share similar job-related challenges (e.g., working with people in crisis situations). Although they differed in their educational background and career history, the results demonstrated that both groups set great value upon generativity values such as helping other people and passing on knowledge, and this was particularly true for outplacement counsellors who have been laid off themselves. Both groups were also more conscientious, agreeable, and emotionally stable than a German norm sample, although outplacement counsellors were more extraverted and emotionally stable than psychotherapists. Furthermore, conscientiousness and neuroticism predicted indicators of career success for both groups. The findings have implications for the qualification of outplacement counsellors.
\end{abstract}

\section{Keywords}

outplacement counselling, work values, personality, career success, psychotherapists

${ }^{1}$ Universität des Saarlandes, Saarbrücken, Germany

*Corresponding author: ckoenig@mx.uni-saarland.de

\section{Introduction}

Losing one's job is tough: Not only does it often mean financial problems, it also comes along with reduced health and well-being, losing contact with former colleagues, and having to find a new job (e.g., Paul \& Moser, 2009). To help people in coping with being laid off, many downsizing companies offer outplacement counselling Aquilanti and Leroux (1999). However, despite the prevalence of downsizing (e.g., Datta, Guthrie, Basuil, \& Pandey, 2010) and an increasing demand for outplacement counselling (cf. Kilcrease, 2013), empirical research is rare. Previous studies have mainly looked at the effectiveness of outplacement counselling for organizations (e.g., Doherty, Tyson, \& Viney, 1993) and clients (Butterfield \& Borgen, 2005; Westaby, 2004), but nearly nothing is known about outplacement counsellors as an occupational group. The present study therefore aimed at describing the outplacement counsellors' profession by examining their work and tasks on the one hand and their personal characteristics on the other, this means, their work values and personality traits. To anchor the description of outplacement counsellors, we compared them with psychotherapists as a distinct but related occupational group. The results regarding their values and personality should help in predicting who might be successful as an outplacement counsellor and allow the drawing of conclusions for their aptitude and qualification, thus improving the quality of the outplacement service.

\section{An Overview of Outplacement Counselling}

Outplacement counselling is a specialised form of career counselling that is offered to employees who have just been laid off (or "terminated") or who are about to lose their jobs. If organizations downsize, they cannot only offer paid time off and severance pay, but also a counselling service that helps their former employees to cope with this often shock-inducing event on the one hand and to find a new job on the other (Aquilanti \& Leroux, 1999; Doherty, 1998). Such outplacement counselling is often provided by specialised firms (Kirk, 1994) and is usually paid for by the downsizing organizations. However, companies hiring such external outplacement counsellors are not only motivated by feeling a social responsibility for their former employees, but also by hoping to reduce costly lawsuits, by sending a signal to the survivors of downsizing (i.e., keeping up their morale), and by saving their public reputation (for further reasons, see Alewell \& Hauff, 2013). It has been estimated that the average cost per employee for outplacement counselling is US\$3,589 (Dvorak \& Lublin, 2009), but the costs likely vary as a function of the hierarchical level of the terminated employee. In Belgium, it is even mandatory to offer outplacement counselling to employees who are 45 years old or older (van de Berge, 2014). According to a recent market analysis of the German Association of Business Consultancies (BDU, 2016), the outplacement industry grows faster than the German economy $(+1.8 \%)$. The total turnover 
of this industry increased from $€ 75$ million in 2015 to $€ 81$ million in 2016.

The goal of outplacement counselling is to help terminated employees to find a fitting job as fast as possible. Aquilanti and Leroux (1999) argued that integral outplacement counselling involves four general phases. Briefly sketched, the first phase of their model is the phase of loss, grieving, and transition, where counsellors help clients to emotionally cope with being fired, the breakdown of their old life, and the induced anger and disappointment. The second phase is the personal development phase, in which counsellors assess the strengths, weaknesses, and interests of their clients, their fears (e.g., regarding help seeking), and also their financial situation. The third phase is the job search phase, where clients update their résumé, activate their personal network, and acquire interview skills (e.g., through training). The fourth phase is the phase of ongoing counselling and support, which provides continuous support to clients in this transition phase of their work life (e.g., reflecting on unsuccessful interviews).

Given the dearth of empirical data on outplacement counselling, it is not surprising that only little is known about its effectiveness. Nevertheless, the evidence so far can be described as suggesting at least some positive, encouraging effects for both the laid-off employees (i.e., clients) and the organizations offering outplacement counselling to their former employees. In a longitudinal study, Westaby (2004) found that more intense and longer lasting outplacement led to better client outcomes, such as an increased likelihood of reemployment. He also reported evidence that intensifying an outplacement counselling program led to higher salaries in the new job. van de Berge (2014), however, found evidence that outplacement may not be effective with a general population but it did seem to help older workers, in particular, to find a new job more quickly. Furthermore, Tzafrir, Mano-Negrin, Harel, and Rom-Nagy (2006) found that an outplacement intervention led to clients' less negative affective responses to their layoff. With regard to organizational outcomes, Doherty et al. (1993) found that providing outplacement counselling helped organizations to maintain the morale of the layoff survivors and the reputation of the company.

\section{The Outplacement Counsellor}

Despite the importance of outplacement counselling for both employees and organizations, empirical research on the role of the outplacement counsellor is rare. Outplacement counsellors, however, have an important job because they guide people through a period of major change. Laid-off employees may lose not only their regular income, but also their regular time structure, their social contacts, and a part of their identity (Jahoda, 1981), which often results in declines in mental health (Paul \& Batinic, 2010; Paul \& Moser, 2009). The work of outplacement counsellors therefore is also challenging: They have to manage the emotions and concerns of the employees losing their jobs and they have to deal with a moral dilemma because their own job is based on their client's plight. Thus, besides expert knowledge about application procedures or the labour market, a range of skills is required of the counsellors that allow them to fulfil their responsibilities toward their clients (cf. Aquilanti \& Leroux, 1999; Kirk, 1994). For example, outplacement counsellors should feel a motivation to help other people, and they should be empathetic to support their clients in this difficult stage of life. These and other work values and personality traits might have an influence on the quality of the services outplacement counsellors provide and, thus, on their own career success (Ng, Eby, Sorensen, \& Feldman, 2005).

To identify which attributes might be important for their work, we compared outplacement counsellors with a meaningful comparison group. Thus, we also collected data of psychotherapists, a related but different group. The differences between both occupational groups should be largely related to educational background, career history, and special work tasks, at least in Germany: German psychotherapists are usually trained as psychologists or physicians and have to acquire certification in psychotherapy, whereas there is no regulated way to become an outplacement counsellor in Germany. Considering their tasks, outplacement counsellors usually help their clients to prepare application materials and offer interview training (Aquilanti \& Leroux, 1999; Kirk, 1994), whereas psychotherapists focus on mental health issues such as depression and anxiety disorders and offer more intense interventions. However, both groups also share similar job-related challenges and, thus, social skills that are necessary to fulfil their jobs. Both help people to cope with critical life events and need to be very sensitive to their clients' needs and emotions.

\section{Work Values of Outplacement Counsellors}

Work values can be defined as "evaluative standards relating to work or the work environment by which individuals discern what is 'right' or assess the importance of preferences" (Dose, 1997, pp.227-228). To describe work values, five clusters comprising 21 values have been proposed: affective values, generativity values, intrinsic growth values, extrinsic growth values, and context-related values (Krumm, Grube, \& Hertel, 2013). Specifically, people valuing intrinsic growth are motivated by outcomes that can be achieved through work itself such as autonomy, self-realization, learning, variety, and achievement. By contrast, people valuing extrinsic growth are motivated by instrumental rewards such as money, status, influence, and advancement. Affective values encompass positive affective experiences and emotional regulation through work such as having an interesting job and social contacts as well as experiencing enjoyment and appreciation. Generativity values are directed toward the next generation and include helping others, doing meaningful work, passing on knowledge, and leaving something behind as a legacy. Finally, context-related values are achieved if a person reaches a desired standard. These include experiencing leisure time, health, security, and stability through work. Differentiating 
these clusters is consistent with other research on work values (e.g., Furnham, Petrides, Tsaousis, Pappas, \& Garrod, 2005; Schwartz, 1999).

As a consequence of their work values, people prefer certain work environments and self-select jobs that satisfy their needs (Brown, 2002; Judge \& Bretz, 1992). A fit between their values and the job, in turn, influences their job satisfaction, performance, commitment, and turnover intentions (for meta-analytic results, see Hoffman \& Woehr, 2006). As far as we know, given the nature of their jobs, both outplacement counsellors and psychotherapists should value the non-instrumental aspects of work (Krumm et al., 2013). Considering generativity values, both groups should be motivated, for example, to help other people or to do meaningful work (e.g., support unemployed and/or ill people). Similarly, intrinsic growth and affective values should be important for both groups because they should both aspire to autonomy (e.g., both groups usually work independently) or try to achieve their goals (e.g., help their clients to overcome their problems); and they should both like to have social contact (e.g., enjoy to communicate with their clients) or to experience appreciation through work (e.g., successful placement or therapy). However, with regard to extrinsic growth and contextrelated values, outplacement counsellors and psychotherapists might differ for the following reasons. The job market for consulting firms is very competitive and there is a pressure to succeed. If they are not successful in placing their clients, they may lose their contracts and, thus, their earnings because they depend on organizations paying for their services. Hence, people choosing this job should be particularly motivated by money, status, influence, and advancement opportunities. In contrast, psychotherapists usually work in independent offices (Destatis, 2017) and receive fixed hourly rates or tariffs for each therapy unit, as is the case with the German health insurance, as one example (GOP, 2000; KBV, 2017), and are therefore not at risk to lose their jobs. Thus, extrinsic growth values should be less important to them. However, they may have chosen the job as a psychotherapist because it offers more job security or stability as compared to the job as an outplacement counsellor.

Based on the previous arguments, the following hypotheses are proposed:

Hypothesis 1: Outplacement counsellors have (a) a higher preference for extrinsic growth values and (b) a lower preference for context-related values as compared to psychotherapists.

Hypothesis 2: Outplacement counsellors and psychotherapists do not differ in their preferences for (a) intrinsic growth values (b) affective values, and (c) generativity values.

\section{Personality Traits of Outplacement Counsellors}

Personality defines an individual's characteristic patterns of thought, feeling, and behaviour and can be described by the Five Factor Model of personality that states five personality traits (cf. Costa \& McCrae, 1992): (a) agreeableness, which describes the tendency to be kind, cooperative, and trust- worthy; (b) conscientiousness, to be organised, achievementoriented, and dependable; (c) extraversion, to be sociable, assertive, and active; (d) emotional stability (also called neuroticism, its negative pole), to be poised, calm, and resistant to stress; and (e) openness, to be creative, curious, and flexible. These personality traits seem to be relevant for the work of both outplacement counsellors (cf. Aquilanti \& Leroux, 1999; Kirk, 1994) and psychotherapists (cf. Keinan, Almagor, \& Ben-Porath, 1989; Topolinski \& Hertel, 2007) because (a) they need to get along with different kinds of clients, (b) they need to be very dependable and organised because they carry a decent amount of responsibility toward those unemployed or mentally ill, (c) they need to be able to communicate with clients, caregivers, or organizations, (d) they have to cope with potentially dramatic emotional responses of their clients and, thus, need inner stability, and (e) they need to be able to adjust to different kinds of people, from the executive to workers with no education.

Such personality traits influence not only people's career choice (e.g., Rogers, Creed, \& Glendon, 2008; Tokar, Fischer, \& Subich, 1998), but also their work outcomes. For example, achievement orientation and dependability (i.e., conscientiousness) seem to be conducive to job performance (for an overview, see Hurtz \& Donovan, 2000). Positive emotionality, sociability, and assertiveness (i.e., extraversion) likely facilitate job satisfaction, building up a network, and becoming promoted (e.g., Seibert \& Kraimer, 2001). By contrast, emotional instability and anxiety (i.e., neuroticism) can provoke dysfunctional job attitudes and, thus, impede effective career management (e.g., Judge \& Bono, 2001; Seibert \& Kraimer, 2001). In line with this, researchers have found positive effects of conscientiousness and extraversion and negative effects of neuroticism on indicators of both objective and subjective career success (e.g., Judge, Higgins, Thoresen, \& Barrick, 1999; Ng et al., 2005; Seibert \& Kraimer, 2001). Based on the previous arguments, the following hypotheses are proposed:

Hypothesis 3: Outplacement counsellors and psychotherapists do not differ in their degrees of (a) agreeableness, (b) conscientiousness, (c) extraversion, (d) neuroticism, and (e) openness to experience.

Hypothesis 4: (a) Conscientiousness and (b) extraversion are positively related and (c) neuroticism is negatively related to participants' career success.

\section{Method}

\section{Samples \\ Outplacement Counsellors}

German outplacement counsellors were found through the German outplacement association (Fachverband Outplacement), which is organised within the German association of business consultancies (Bundesverband Deutscher Unternehmensberatung), by visiting three internet pages that list con- 
sultancies offering outplacement counselling 123 , and by searching the internet version of the German Yellow pages. This search identified 123 outplacement consultancies, which were contacted by phone and asked whether a link to an online questionnaire could be forwarded to their counsellors. Fifty outplacement counsellors participated. Of these, 24 were women and 25 men (plus one additional person who did not provide gender information). They were on average 52 years old $(S D=10.12)$, with age ranging from 31 to 71 years, and had an average tenure with the organizations of 11 years $(S D=$ 9.25). Twenty-seven (54\%) had a university degree, ten (20\%) had a university of applied sciences degree (i.e., offering more practical oriented programs in the German tertiary education system), eight (16\%) had completed vocational training, and five $(10 \%)$ had an additional doctoral degree. Their subject areas were economics (38\%), social sciences (24\%), psychology $(20 \%)$, and other subjects (18\%; e.g., computer sciences, and engineering). Nearly all $(n=47)$ counselled individual persons (as opposed to groups of people) and the average time to placement was five months $(S D=2.60)$.

\section{Psychotherapists}

In Germany, psychotherapists need to have a licensure ("Approbation") to practice psychotherapy ${ }^{4}$. According to German law, a licensure can be obtained by extensive postgraduate training after having received a Master's-level equivalent degree in psychology or medicine. Psychotherapists were found through the German association of psychotherapists (Deutsche Psychotherapeuten Vereinigung), by visiting two German internet pages that list psychotherapists ${ }^{56}$, and by searching the internet version of the German Yellow pages. Of the 377 individuals contacted, 54 filled out the questionnaire, indicating a response rate of $14 \%$. Two individuals did not have their approbation (i.e., their licensure for psychotherapy, which is mandatory in Germany), and were therefore excluded, resulting in a final $n$ of 52. Of these, 31 were women and 21 were men. They were on average 53 years old $(S D=9.15)$, with age ranging from 33 to 70 years, and had an average tenure of 14 years with their organization $(S D=10.26)$. All of them had a university degree in either psychology $(n=$ $47)$ or medicine $(n=5) ; 12$ also had a doctoral degree. The majority $(92 \%)$ worked independently in their own offices; the remaining were employed in mental hospitals. Therapeutic orientation was cognitive behaviour therapy (50\%), psychodynamic therapy and psychoanalysis $(40 \%)$, or multiple forms of therapy $(10 \%)$.

\footnotetext{
${ }^{1}$ www.outplacement-kosten.de

${ }^{2}$ www.perwiss.de

${ }^{3}$ www.personalwirtschaft.de

${ }^{4}$ wwww.europsyche.org/contents/14283/germany

${ }^{5}$ www.therapeuten.de

${ }^{6}$ www.deutschepsychotherapeutenvereinigung.de
}

\section{Measures \\ Work values}

To measure work values, the Munster Work Value Measure (Krumm et al., 2013) was used. This measure differentiates between 21 values sorted into the five clusters previously mentioned: intrinsic growth values, extrinsic growth values, affective values, generativity values, and context-related values. Participants were asked to indicate the subjective importance of each of the values by using a visual analogue scale: They moved a slider on a continuous scale with the endpoints labelled as very unimportant vs. very important. The position of the slider was then calculated into integer data points ranging from 0 (minimum) to 100 (maximum). A sample intrinsic growth value is variety, assessed with the question "How important is variety to you at work?"; an extrinsic growth value is advancement (i.e., "How important is it to you to advance your career?"); an affective value is social contact (i.e., "How important is social contact to you at work?"); a generativity value is helping (i.e., "How important is to you to help other people?"); and a context-related value is security (i.e., "How important is it to you to have a secure job?"). Reliability scores are displayed in Table 1 and are comparable to those of the original scale of Krumm et al. (2013).

\section{Personality traits}

The Big Five personality traits: agreeableness, conscientiousness, extraversion, neuroticism, and openness, were measured using the BFI-K scale (Rammstedt \& John, 2005), an established German short version of the Big Five Inventory (BFI; John, Naumann, \& Soto, 2008). It comprises 21 short phrases (e.g., "I see myself as someone who is outgoing, sociable" for extraversion) that participants rated on a 5-point Likert scale from $1=$ strongly disagree to $5=$ strongly agree. The reliability scores are displayed in Table 3 and are comparable to those of the original scale of Rammstedt and John (2005). Rammstedt and John (2005) also reported the data of a norm sample of 391 people that were used as a third comparison category.

\section{Career success}

Participants' subjective career success was measured using the career satisfaction scale developed by Greenhaus, Parasuraman, and Wormley (1990). Participants answered five items on a Likert scale ranging from $1=$ strongly disagree to 5 = strongly agree. A sample item is: "I am satisfied with the progress I have made toward meeting my overall career goals." Objective career success was measured by inquiring about participants' income per year before tax $(1=$ below $€ 40,001$, 2 = between $€ 40,001$ and $€ 80,000,3=$ between $€ 80,001$ and $€ 120,000,4=$ between $€ 120,001$ and $€ 160,000,5=$ between $€ 160,001$ and $€ 200,000,6=$ above $€ 200,000)$.

In addition, a series of questions addressing participants' educational background were asked (e.g., "What is your highest educational degree?", "What is your educational subject?", "Have you ever been laid off?"). Outplacement counsellors were also asked about their career history (e.g., "What kind 
of jobs have you done in your previous career?", "Why did you decide to become an outplacement counsellor?"), using an open response format, allowing multiple answers. Both groups also indicated how frequently they engage in specific work tasks (e.g., "Helping to cope with grief and shock"), using a 5-point scale ranging $(1=$ never to $5=$ very frequently $)$.

\section{Results}

As suggested, psychotherapists were characterised by having a straight career (i.e., all of them were trained as psychologists or physicians and had licensure in psychotherapy), whereas outplacement counsellors showed a remarkably large variety of educational degrees and subjects. Most became outplacement counsellors at a later stage of their careers, after having been, for example, a business consultant (68\%), a human resource manager $(36 \%)$, an instructor (18\%), a marketing manager $(18 \%)$, or a project manager $(10 \%)$. Many of them selected the job to help other people (40\%), to have an interesting job (30\%), and to share knowledge and experiences $(30 \%)$, thus emphasizing the importance of both affective and generativity values. For others, outplacement counselling served as a supplement to their previous work $(22 \%)$ or as a strategic decision $(10 \%)$. These motives may be a result of their own layoff experiences: Twenty-five (50\%) of them had been laid off before becoming an outplacement counsellor. In comparison, only four psychotherapists $(8 \%)$ had lost their job in the past.

The work tasks of outplacement counsellors in comparison to that of psychotherapists are displayed in Table 1. Some work tasks are distinctive to outplacement counsellors' and psychotherapists' professional competences and specialties (i.e., job services versus mental diseases). For example, outplacement counsellors assist their clients in preparing job interviews and building a network, whereas psychotherapists make diagnoses (at least in Germany) and help their clients to cope with psychopathological problems. However, there are also comparable work tasks: Both groups help their clients to cope with grief and shock and support their self-reflection. They also assess strength and resources, set goals, and promote the self-development of their clients.

Means, standard deviations, Cronbach's alpha coefficients, and correlations among the variables are displayed in Table 3. Figure 1 shows the work values of outplacement counsellors in comparison to psychotherapists. Contrary to Hypothesis 1a, the groups did not differ in extrinsic growth values, $t(100)=0.39, p>.05$; thus, outplacement counsellors and psychotherapists showed a similar (low) motivation by money, status, influence, and advancement (all $p$ 's > .05). In line with Hypothesis 1b, psychotherapists exhibited a stronger motivation for context-related values than outplacement counsellors, $t(100)=-5.20, p<.001, d=1.03$. In particular, psychotherapists reported higher scores on security, $t(100)=-5.74, p$ $<.001, d=1.13$, and stability, $t(100)=5.16, p<.001, d=$ 1.02. In addition, outplacement counsellors who had been laid off reported slightly lower levels of motivation by security than those who had not been laid off, $t(48)=-1.70, p=.096$, $d=0.48$. However, there were no differences regarding the importance of leisure time and health (all $p$ 's > .05).

Although both groups were motivated by intrinsic growth values and affective values, outplacement counsellors had higher scores than psychotherapists, $t(100)=2.52, p<.05, d$ $=0.50$ for intrinsic growth values and $t(100)=2.77, p<.01, d$ $=0.55$ for affective values, thus disconfirming Hypotheses $2 \mathrm{a}$ and $2 \mathrm{~b}$. Specifically, outplacement counsellors had a stronger motivation for achievement, $t(100)=4.45, p<.001, d=0.89$, variety, $t(100)=3.46, p<.01, d=0.69$, social contact, $t(100)=$ $3.05, p<.01, d=0.61$, and appreciation, $t(100)=2.20, p<.05$, $d=0.44$, than psychotherapists. However, both groups did not differ in terms of their valuation of autonomy, self-realization, learning, having an interesting job, and enjoyment (all p's > .05). In line with Hypothesis $2 \mathrm{c}$, both groups did not differ in their motivation for generativity values, $t(100)=1.56, p>.05$. It was therefore similarly important for both groups to help other people, to do meaningful work, to pass on knowledge, and to leave something behind as a legacy (all $p$ 's $>.05$ ). Nevertheless, it was found that outplacement counsellors who had been laid off exhibited a stronger motivation to pass on knowledge, $t(48)=2.38, p<.05, d=0.67$, and to help other people, $t(48)=2.68, p<.01, d=0.76$, than those who had not been laid off.

The results regarding the personality traits of outplacement counsellors in comparison to psychotherapists and the norm sample (Rammstedt \& John, 2005) are shown in Table 2. In line with Hypotheses $3 \mathrm{a}, 3 \mathrm{~b}$, and $3 \mathrm{e}$, outplacement counsellors and psychotherapists did not differ in terms of agreeableness, conscientiousness, and openness. Both groups were also more agreeable and conscientious than the norm sample. However, counsellors exhibited a higher score on extraversion and a lower score on neuroticism than psychotherapists, thus disconfirming Hypothesis $3 \mathrm{c}$ and $3 \mathrm{~d}$. Nevertheless, both groups were less neurotic than the norm sample.

Regarding work outcomes, the results show significant positive relationships between both conscientiousness and extraversion, and career satisfaction, and a significant negative relationship between neuroticism and career satisfaction, thus supporting Hypotheses $4 \mathrm{a}, 4 \mathrm{~b}$, and $4 \mathrm{c}$ for intrinsic career success. In addition, the results showed a significant positive relationship between conscientiousness and salary and a significant negative relationship between neuroticism and salary, thus supporting Hypotheses $4 \mathrm{a}$ and $4 \mathrm{c}$ for extrinsic career success. As expected, there were no significant effects of agreeableness and openness (for detailed results, see Table 2).

\section{Discussion}

Given the prevalence of downsizing, many people are affected by job loss at some point in their working life-in times such as the COVID-19 pandemic, for instance, job losses across occupations, sectors, and geographic location may occur concurrently across the world. Outplacement counsellors 


\section{Figure 1}

Work values of outplacement counsellors and psychotherapists. Higher scores indicate a higher importance of the values (from $0=$ very unimportant to $100=$ very important). Error bars represent standard errors of the means.

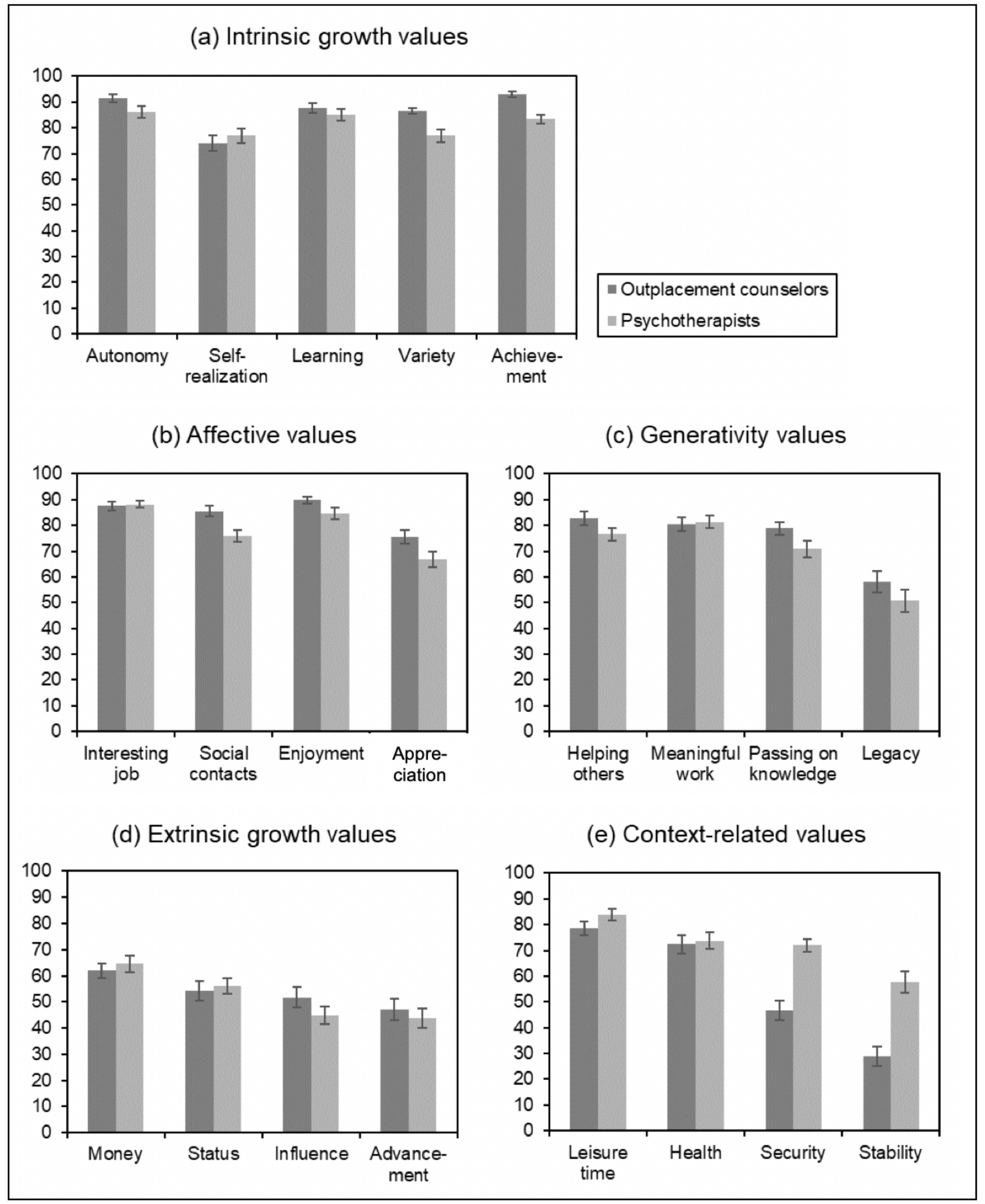


Table 1

Work Tasks of Outplacement Counsellors and Psychotherapists

\begin{tabular}{|c|c|c|c|c|c|c|}
\hline & \multicolumn{2}{|c|}{$\begin{array}{l}\text { Outplacement } \\
\text { counsellors } \\
(n=50)\end{array}$} & \multicolumn{2}{|c|}{$\begin{array}{l}\text { Psycho- } \\
\text { therapists } \\
(n=52)\end{array}$} & \multirow[b]{2}{*}{$t(100)$} & \multirow[b]{2}{*}{$d$} \\
\hline & $M$ & $S D$ & $M$ & $S D$ & & \\
\hline Preparing the résumé of clients & 4.80 & 0.50 & \multicolumn{2}{|c|}{$\mathrm{n} / \mathrm{a}$} & \multicolumn{2}{|l|}{$\mathrm{n} / \mathrm{a}$} \\
\hline Preparing clients for job interviews & 4.76 & 0.43 & \multicolumn{2}{|c|}{$\mathrm{n} / \mathrm{a}$} & \multicolumn{2}{|l|}{$\mathrm{n} / \mathrm{a}$} \\
\hline Building a network of contacts & 4.26 & 0.97 & \multicolumn{2}{|c|}{$\mathrm{n} / \mathrm{a}$} & \multicolumn{2}{|l|}{$\mathrm{n} / \mathrm{a}$} \\
\hline Searching for and brokering of open positions & 3.32 & 1.24 & \multicolumn{2}{|c|}{$\mathrm{n} / \mathrm{a}$} & \multicolumn{2}{|l|}{$\mathrm{n} / \mathrm{a}$} \\
\hline Participating in the dismissal meeting/direct help afterwards & 2.18 & 1.00 & \multicolumn{2}{|c|}{$\mathrm{n} / \mathrm{a}$} & \multicolumn{2}{|l|}{$\mathrm{n} / \mathrm{a}$} \\
\hline Assessing strength and resources of clients & 4.78 & 0.42 & 4.23 & 1.13 & $-3.23 * *$ & 0.65 \\
\hline Setting goals (e.g., personal or career goals) & 4.76 & 0.52 & 3.44 & 1.26 & $-6.86 * * *$ & 1.37 \\
\hline Supporting the self-reflection of clients & 4.52 & 0.86 & 4.58 & 0.64 & 0.38 & 0.08 \\
\hline Helping to cope with grief and shock & 3.78 & 1.06 & 3.42 & 0.96 & -1.79 & 0.36 \\
\hline Promoting self-development & 3.62 & 1.05 & 2.96 & 1.30 & $-2.81 * *$ & 0.56 \\
\hline Helping to cope with stress (e.g., problem solving skills) & 3.60 & 1.13 & 4.17 & 0.96 & $2.77 * *$ & 0.54 \\
\hline $\begin{array}{l}\text { Handling problems caused by losing the job (e.g., loss of the daily } \\
\text { routine) }\end{array}$ & 3.56 & 1.25 & 3.50 & 0.78 & -0.29 & 0.06 \\
\hline Coping with psychopathological problems of clients & 2.46 & 1.15 & 4.52 & 1.00 & $9.68^{* * *}$ & 1.91 \\
\hline Psychological diagnostics of clients & \multicolumn{2}{|c|}{$\mathrm{n} / \mathrm{a}$} & 4.44 & 0.87 & $\mathrm{n} / \mathrm{a}$ & \\
\hline
\end{tabular}

Note: Participants answered on a 5 -point scale from $1=$ never to $5=$ very frequently. ${ }^{*} p<.05 . * * p<.01 . * * * p<.001$.

help laid-off employees to cope with this major change, support them to find a new job, they therefore need various skills to fulfil their work properly (e.g., Aquilanti \& Leroux, 1999; Kirk, 1994; Westaby, 2004). Thus, outplacement counselling involves not only the client and the organization, but the outplacement counsellor themselves. Nevertheless, information about outplacement counsellors is rare even though it seems reasonable that their personal characteristics, attitudes, and behaviours largely determine the quality and success of the outplacement service. The present study therefore examined the characteristics of outplacement counsellors and compared them to psychotherapists. The results showed some expected and some unexpected similarities and differences between both groups.

Considering their educational background and career history, the results were as expected. There is likely no standard way of becoming an outplacement counsellor. In fact, they came from a variety of fields and had a variety of previous jobs. There also do not seem to be any minimal educational requirements for this job. This is consistent with the finding that half of the participants became outplacement counsellors as a result of their own layoff experiences, which suggests that layoff experiences may be an additional trigger for this career decision. At the same time, if there are no minimal educational requirements, this implies a need for standardised education, in particular because outplacement counsellors fulfil tasks similar to psychotherapists, such as dealing with shocking events or providing stress management strategies. For example, universities could offer advanced certificates in outplacement counselling, or the outplacement industry could establish standards for outplacement counselling training.

The motivation for choosing a specific job, however, de- pends on personal characteristics and attitudes, such as individuals' work values (Brown, 2002; Judge \& Bretz, 1992), and people are central to the work of both outplacement counsellors and psychotherapists. It was therefore not surprising that both groups put similar emphasis on generativity values such as helping other people and passing on knowledge. This was especially true for those outplacement counsellors who had been laid off and who therefore were more motivated to support people who were in the same difficult situation they experienced in the past. Thus, the decision to become an outplacement counsellor seems to be shaped by personal experiences as well as work values. Given that outplacement is a special kind of counselling service, clients might also benefit from a counsellor who shares their experiences and who knows about the concerns and challenges to start a new career, thus strengthening the perceived integrity and trustworthiness of the counsellor. Future research should therefore examine the impact of outplacement counsellors' layoff experiences and generativity values on the quality and success of their services, for example in terms of the quality of the counsellor-client relationship and the actual placement rate.

In addition, outplacement counsellors and psychotherapists set great value upon intrinsic work values such as working autonomously as well as upon affective values such as having an interesting job, which seem to be desirable goals for employees in general (Bipp, 2010). However, the work itself was central to both outplacement counsellors and psychotherapists, which might be one reason why extrinsic rewards were less important. Lastly, the results supported the suggestion that context-related values such as having a stable and secure job are less relevant for outplacement counsellors than for psychotherapists. Whereas they might have chosen the job 
Table 2

Big Five Personality Scores of Outplacement Counsellors in Comparison to

Psychotherapists and a German Norm Sample

\begin{tabular}{lcccccc}
\hline & $\begin{array}{c}\text { Outplacement counsellors } \\
(n=50)\end{array}$ & \multicolumn{2}{c}{$\begin{array}{c}\text { Psychotherapists } \\
(n=52)\end{array}$} & \multicolumn{2}{c}{$\begin{array}{c}\text { Norm sample } \\
(n=391)\end{array}$} \\
& $M$ & $S D$ & $M$ & $S D$ & $M$ & $S D$ \\
\hline Agreeableness & $3.56_{a}$ & 0.71 & $3.61_{a}$ & 0.62 & $2.89_{b}$ & 1.16 \\
Conscientiousness & $4.13_{a}$ & 0.49 & $3.93_{a}$ & 0.68 & $3.47_{b}$ & 0.96 \\
Extraversion & $4.03_{a}$ & 0.73 & $3.58_{b}$ & 0.8 & $3.55_{b}$ & 1.03 \\
Neuroticism & $2.18_{a}$ & 0.65 & $2.53_{b}$ & 0.74 & $3.11_{c}$ & 1.16 \\
Openness & $4.12_{a}$ & 0.61 & $4.26_{a}$ & 0.59 & $4.00_{a}$ & 0.95 \\
\hline
\end{tabular}

Note: The norm sample is reported in Rammstedt and John (2005). Means that do not share the same subscript (line-by-line reading) were significant different from each other $(p<.025$, due to a Bonferroni correction

because of specific job characteristics, their low motivation for context-related values might also be a result of their work as an outplacement counsellor. Working with people who have just been laid off tells them that job loss is an integral part of the present-day world of work (see also Aquilanti \& Leroux, 1999), and many of the participating outplacement counsellors had first-hand experience of a personal layoff, and might therefore have adapted their attitudes toward job stability and security. Furthermore, outplacement counsellors have to allay their clients' fears and describe career change as something positive (Aquilanti \& Leroux, 1999; Kirk, 1994). They may even have to persuade their clients to perceive the layoff as being the starting point for exploring a new career (Noer, 1993). Thus, keeping to traditional values such as job stability and security might be rather obstructive.

With regards to their personality traits, both outplacement counsellors and psychotherapists were similarly agreeable, conscientious, and open to new experiences, but more agreeable, conscientious, and emotionally stable than the norm sample. These results indicate that the demands of both jobs are similar to each other, but exceed the standards of many other jobs: Outplacement counsellors and psychotherapists work with people in dire straits and have to be empathetic and sensitive to their clients' needs; thus, people who are highly agreeable (e.g., cooperative), conscientious (e.g., dependable), and emotionally stable (e.g., less neurotic) might have been more likely to choose the job. Furthermore, it might be possible that people characterised by these traits were more able to meet the challenges and to persist in these jobs. Contrary to the expectations, outplacement counsellors were not only more extroverted and emotionally stable than the norm sample, but also than psychotherapists. One reason for this might be the marketing aspect of their work because they have to communicate with organizations and other stakeholders and promote their services proactively in order to acquire new clients. The finding that psychotherapists were less emotionally stable than outplacement counsellors was unexpected. A possible explanation might be that ther- apists were more likely to have experienced mental health problems in the past, and this might have motivated them to become psychotherapists (for supportive evidence for this idea see, e.g., Murphy \& Halgin, 1995). Alternatively, regular clinical supervision with colleagues might have brightened psychotherapists' self-reflection, thus resulting in more conservative response patterns.

Nevertheless, both groups were highly satisfied with their jobs, probably because they do not only have a need to help their clients, but because they actually do help: They support them in finding a new job or in managing their problems. Although outplacement counsellors work in an environment of layoffs, they are only rarely involved in communicating layoff decisions (see Table 1), which has been found to be an unpleasant task for the messengers of bad news (Richter, König, Koppermann, \& Schilling, 2016); thus, the positive characteristics of the job seem to outweigh the negative ones. Furthermore, personality traits influenced their subjective and objective career success in the expected way (Judge et al., 1999; Ng et al., 2005; Seibert \& Kraimer, 2001): People high in conscientiousness (and extraversion) and people low in neuroticism were not only more satisfied with their career, they also earned more than those low in conscientiousness and those high in neuroticism. These results suggest that outplacement counsellors who are conscientious and emotionally stable are more successful in providing their services (e.g., Hurtz \& Donovan, 2000; Judge \& Bono, 2001), for example in terms of dealing with their clients' problems adequately, teaching them necessary skills effectively, and successfully finding them a new job, and are therefore also more successful in managing their own career (cf. Ng et al., 2005). Since the demand for a specific consultancy firm probably depends on "word-of-mouth recommendation," the actual effectiveness of the counsellor (e.g., the placement rate) and the client's perspective (e.g., the satisfaction with the counsellor and/or the attitudes about the new job) should both be considered in order to provide a comprehensive picture of the overall quality of the outplacement service. 


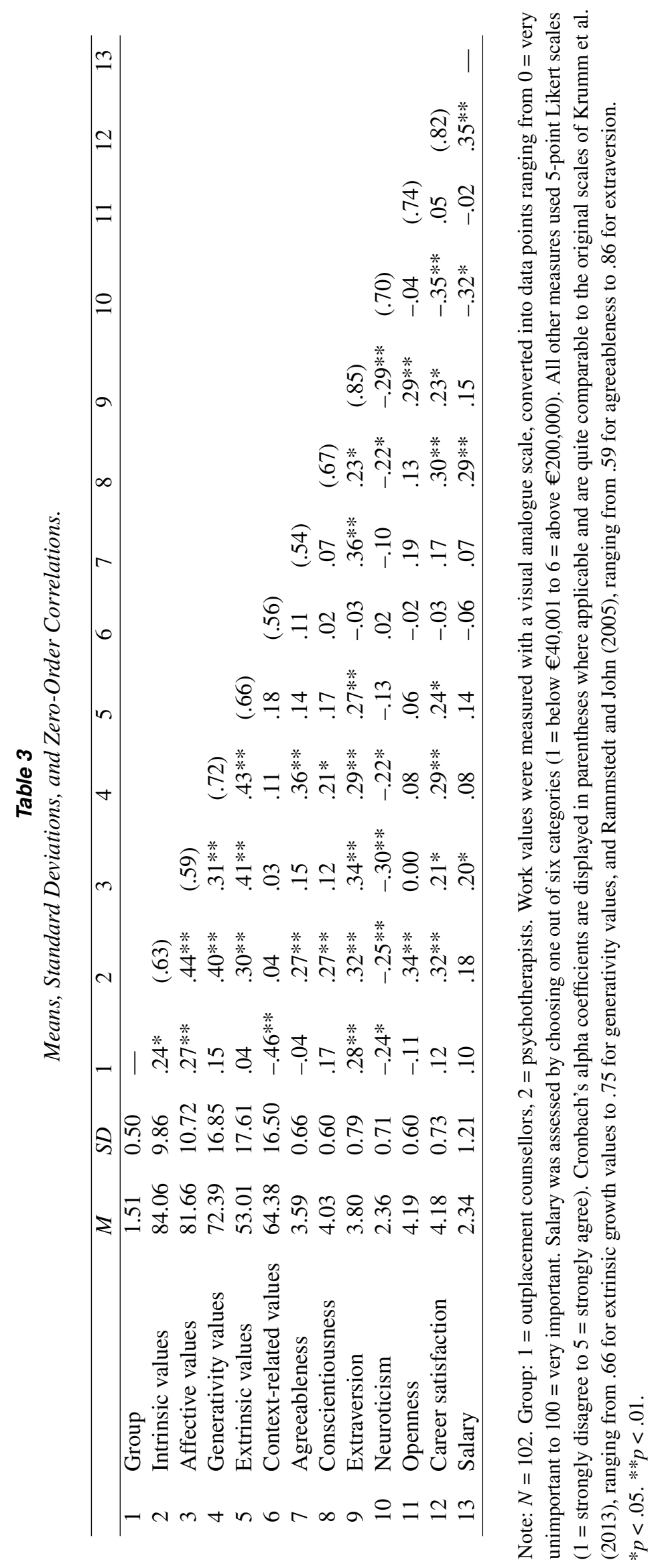


As is true for all research, the present study is not free of limitations. First, only German outplacement counsellors were surveyed, and legal differences and labour regulations (e.g., employment protection regulations, compensation packages) might also have implications for the work of outplacement counsellors. Thus, comparative studies in other countries would be welcomed. Second, it could be argued that the sample size could have been larger. However, it should be noted that only 123 listed outplacement consultancies were found, suggesting that the participants already represented a substantial part of this highly specialised market. Nevertheless, the sample was limited to external outplacement counsellors and future research should try to compare them to internal or inhouse outplacement counsellors (cf. Kilcrease, 2013), who are often represented by human resource managers providing counselling services as an extension of their normal duties. In particular, researchers should address the potential moral conflict arising from the internal counsellors' role within the company (i.e., counselling their laid-off colleagues, but keeping their own job within the company) and its consequences for the counsellors' well-being and performance. Third, one might put into question that psychotherapists were used instead of other business counsellors as a comparison group. Nevertheless, different occupational groups were considered however psychotherapists were intentionally chosen because they have a similar clientele (i.e., people in a crisis situation) and have to manage similar (emotional) challenges. However, future research could compare the work values and personality traits of people who are interested in becoming, and those who already work as outplacement counsellors in order to find out whether these characteristics influence job choice (e.g., Judge \& Bretz, 1992; Rogers et al., 2008; Tokar et al., 1998) or vice versa. Furthermore, future studies should also consider objective indicators of outplacement counsellors' career success, for instance in terms of their actual placement rate.

\section{Summary and Conclusion}

Outplacement counselling is a service provided to support laid-off employees' realignment. Outplacement counsellors help these people to cope with the stressful layoff experience, to acquire new skills and to find a new job. The present study has shown that outplacement counsellors are characterised by certain work values and personality traits that are comparable to those of psychotherapists, indicative of the centrality of helping people, and important for their career success. Given the high demands of the job, it is important that outplacement counsellors receive adequate training to help them fulfil their responsibility toward their clients.

\section{Funding}

This research received no external funding.

\section{Conflict of Interest}

The authors declare that they have no competing interests.

\section{References}

Alewell, D., \& Hauff, S. (2013). Employers' motives behind outplacement activities. Personnel Review, 42(4), 466487.

Aquilanti, T. M., \& Leroux, J. (1999). An integrated model of outplacement counseling. Journal of Employment Counseling, 36(4), 177-191.

BDU. (2016). Outplacementberatung in Deutschland 2015/2016 [Outplacement services in Germany 2015/2016]. Bonn, Germany: Bundesverband Deutscher Unternehmensberater BDU e.V.

Bipp, T. (2010). What do people want from their jobs? the Big Five, core self-evaluations and work motivation. International Journal of Selection and Assessment, 18(1), 28-39.

Brown, D. (2002). The role of work and cultural values in occupational choice, satisfaction, and success: A theoretical statement. Journal of Counseling \& Development, 80(1), 48-56.

Butterfield, L. D., \& Borgen, W. A. (2005). Outplacement counseling from the client's perspective. The Career Development Quarterly, 53(4), 306-316.

Costa, P. T. J., \& McCrae, R. R. (1992). Revised NEO Personality Inventory (NEO-PI-R) and NEO Five-Factor Inventory (NEO-FFI) professional manual. Odessa, FL: PAR.

Datta, D. K., Guthrie, J. P., Basuil, D., \& Pandey, A. (2010). Causes and effects of employee downsizing: A review and synthesis. Journal of Management, 36(1), 281348 .

Destatis. (2017). Gesundheit: Personal 2015 [Health: Staff 2015]. Wiesbaden, Germany: Statistisches Bundesamt. Retrieved from https://www. destatis . de/DE/Publikationen/Thematisch/

DienstleistungenFinanzdienstleistungen/ Kostenstruktur/

KostenstrukturAerzte2020161119004 -pdf?_blob=publicationfile

Doherty, N. (1998). The role of outplacement in redundancy management. Personnel Review, 27(4), 343-353.

Doherty, N., Tyson, S., \& Viney, C. (1993). A positive policy? Corporate perspectives on redundancy and outplacement. Personnel Review, 22(1), 45-53.

Dose, J. J. (1997). Work values: An integrative framework and illustrative application to organizational socialization. Journal of Occupational and Organizational Psychology, 70(3), 219-240.

Dvorak, P., \& Lublin, J. S. (2009). Outplacement firms struggle to do job. Wall Street Journal. Retrieved from http: / / www.ws j.com/articles / SB125069793645343423

Furnham, A., Petrides, K., Tsaousis, I., Pappas, K., \& Garrod, D. (2005). A cross-cultural investigation into the relationships between personality traits and work values. The Journal of Psychology, 139(1), 5-32. 
GOP. (2000). Gebührenordnung für Psychologische Psychotherapeuten und Kinder-und Jugendlichenpsychotherapeuten [German tariff for psychological psychotherapists and child and adolescent psychotherapists] $\S 1$.

Greenhaus, J. H., Parasuraman, S., \& Wormley, W. M. (1990). Effects of race on organizational experiences, job performance evaluations, and career outcomes. Academy of Management Journal, 33(1), 64-86.

Hoffman, B. J., \& Woehr, D. J. (2006). A quantitative review of the relationship between person-organization fit and behavioral outcomes. Journal of Vocational Behavior, 68(3), 389-399.

Hurtz, G. M., \& Donovan, J. J. (2000). Personality and job performance: The Big Five revisited. Journal of Applied Psychology, 85(6), 869-879.

Jahoda, M. (1981). Work, employment, and unemployment: Values, theories, and approaches in social research. American Psychologist, 36(2), 184-191.

John, O. P., Naumann, L. P., \& Soto, C. J. (2008). Paradigm shift to the integrative Big-Five trait taxonomy: History, measurement and conceptual issues. In O. P. John, R. W. Robins, \& L. A. Pervin (Eds.), Handbook of personality: Theory and research (3rd ed., p. 114-258). New York, NY: Guilford Press.

Judge, T. A., \& Bono, J. E. (2001). Relationship of core self-evaluations traits—-self-esteem, generalized selfefficacy, locus of control, and emotional stability-with job satisfaction and job performance: A meta-analysis. Journal of Applied Psychology, 86(1), 80-92.

Judge, T. A., \& Bretz, R. D. (1992). Effects of work values on job choice decisions. Journal of Applied Psychology, 77(3), 261-271.

Judge, T. A., Higgins, C. A., Thoresen, C. J., \& Barrick, M. R. (1999). The Big Five personality traits, general mental ability, and career success across the life span. Personnel Psychology, 52(3), 621-652.

KBV. (2017). Kassenärztliche Bundesvereinigung [National Association of Statutory Health Insurance Physicians Germany], Einheitlicher Bewertungsmaßstab (EBM): Psychotherapie [Valuation standard for psychotherapy].

Keinan, G., Almagor, M., \& Ben-Porath, Y. S. (1989). A reevaluation of the relationship between psychotherapeutic orientation and perceived personality characteristics. Psychotherapy: Theory, Research, Practice, Training, 26(2), 218-226.

Kilcrease, K. M. (2013). Outplacement services for displaced employees: Attitudes of human resource managers based on differences in internal and external delivery. Journal of Employment Counseling, 50(1), 2-13.

Kirk, J. J. (1994). Putting outplacement in its place. Journal of Employment Counseling, 31(1), 10-18.

Krumm, S., Grube, A., \& Hertel, G. (2013). The munster work value measure. Journal of Managerial Psychology,
28(5), 532-560.

Murphy, R. A., \& Halgin, R. P. (1995). Influences on the career choice of psychotherapists. Professional Psychology: Research and Practice, 26(4), 422-426.

Ng, T. W., Eby, L. T., Sorensen, K. L., \& Feldman, D. C. (2005). Predictors of objective and subjective career success: A meta-analysis. Personnel Psychology, 58(2), 367-408.

Noer, D. M. (1993). Healing the wounds: Overcoming the trauma of layoffs and revitalizing downsized organizations. San Fransisco, CA: Jossey-Bass.

Paul, K. I., \& Batinic, B. (2010). The need for work: Jahoda's latent functions of employment in a representative sample of the German population. Journal of Organizational Behavior, 31(1), 45-64.

Paul, K. I., \& Moser, K. (2009). Unemployment impairs mental health: Meta-analyses. Journal of Vocational behavior, 74(3), 264-282.

Rammstedt, B., \& John, O. P. (2005). Kurzversion des Big Five inventory (BFI-K): Entwicklung und Validierung eines ökonomischen Inventars zur Erfassung der fünf Faktoren der Persönlichkeit [Short version of the Big Five Inventory (BFI-K): Development and validation of an economic inventory for assessment of the five factors of personality]. Diagnostica, 51(4), 195-206.

Richter, M., König, C. J., Koppermann, C., \& Schilling, M. (2016). Displaying fairness while delivering bad news: Testing the effectiveness of organizational bad news training in the layoff context. Journal of Applied Psychology, 101(6), 779-792.

Rogers, M. E., Creed, P. A., \& Glendon, A. I. (2008). The role of personality in adolescent career planning and exploration: A social cognitive perspective. Journal of Vocational Behavior, 73(1), 132-142.

Schwartz, S. H. (1999). A theory of cultural values and some implications for work. Applied Psychology: An International Review, 48(1), 23-47.

Seibert, S. E., \& Kraimer, M. L. (2001). The Five-Factor Model of personality and career success. Journal of Vocational Behavior, 58(1), 1-21.

Tokar, D. M., Fischer, A. R., \& Subich, L. M. (1998). Personality and vocational behavior: A selective review of the literature, 1993-1997. Journal of Vocational Behavior, 53(2), 115-153.

Topolinski, S., \& Hertel, G. (2007). The role of personality in psychotherapists' careers: Relationships between personality traits, therapeutic schools, and job satisfaction. Psychotherapy Research, 17(3), 365-375.

Tzafrir, S. S., Mano-Negrin, R., Harel, G. H., \& Rom-Nagy, D. (2006). Downsizing and the impact of job counseling and retraining on effective employee responses. Career Development International, 11(2), 125-144.

van de Berge, W. (2014, April). Displaced workers and the effects of outplacement and severance pay. Paper presented at the 2nd NEUJOBS Validation Event, Bonn, 
Germany.

Westaby, J. D. (2004). The impact of outplacement programs on reemployment criteria: A longitudinal study of displaced managers and executives. Journal of Employment Counseling, 4l(1), 19-28. 